\title{
Erratum to: Ultra-High Tribological Performance of Magnetron Sputtered a-C:H Films in Sand-Dust Environment
}

\author{
Jianwei Qi • Liping Wang · Fengyuan Yan • \\ Qunji Xue
}

Published online: 12 June 2010

(C) Springer Science+Business Media, LLC 2010

\section{Erratum to: Tribol Lett \\ DOI 10.1007/s11249-009-9574-8}

In the original version of this paper, the unit $10^{-19} \mathrm{~m}^{3} / \mathrm{N} \mathrm{m}$ is not correct.

Incorrect unit: $10^{-19} \mathrm{~m}^{3} / \mathrm{N} \mathrm{m}$

Correct unit: $\times 10^{-16} \mathrm{~m}^{3} / \mathrm{N} \mathrm{m}$

The incorrect unit should be changed in the following places:

\begin{abstract}
It is very interesting $\ldots$ order of magnitude $\left(\times 10^{-16} \mathrm{~m}^{3} /\right.$ $\mathrm{N} \mathrm{m)} \ldots$.

3.2 Effect of Load and the Amount of Sand on the Wear Rate of a-C:H Films

The wear rate of a-C:H film sliding against AISI 1045 steel ... Under the dry sliding condition without sand, the wear rate reached a second highest value of about $11 \times 10^{-16} \mathrm{~m}^{3} / \mathrm{N} \mathrm{m}$ at $1 \mathrm{~N}$ and rapidly fell down to a
\end{abstract}

The online version of the original article can be found under doi:10.1007/s11249-009-9574-8.

J. Qi · L. Wang $(\bowtie) \cdot$ F. Yan · Q. Xue

State Key Laboratory of Solid Lubrication,

Lanzhou Institute of Chemical Physics,

Chinese Academy of Sciences, Lanzhou 730000,

People's Republic of China

e-mail: lpwang@licp.ac.cn

J. Qi

Graduate School of Chinese Academy of Sciences, Beijing

100039, People's Republic of China stable value with by increasing the load to 3,5 and $7 \mathrm{~N} \ldots$ The complicated variations in the wear rate were observed under wear condition with the least amount of sand, in which the wear rate exhibited initial drop from $7.5 \times 10^{-16}$ to $5.5 \times 10^{-16} \mathrm{~m}^{3} / \mathrm{N} \mathrm{m}$, and then increased to the original value and finally fell down to $6.0 \times 10^{-16} \mathrm{~m}^{3} /$ $\mathrm{N} \mathrm{m}$. This could be attributed to random variation in contact surface during the wear process caused by the random movement of small amount of sand.

3.3 The Effect of Sand Particle Size on the Friction and Wear Behavior

It can be seen from Fig. 7 that the influences of different particle size but show the highest value of $8.015 \times 10^{-16} \mathrm{~m}^{3} / \mathrm{N} \mathrm{m}$ at $97-180 \mathrm{~lm}$ size range. Specifically, the lowest value of the wear rate is $4.58 \times 10^{-16} \mathrm{~m}^{3} /$ $\mathrm{N} \mathrm{m}$ for films under the dry sliding condition and the wear rate of films under sand-dust conditions vary between $5.75 \times 10^{-16} \mathrm{~m}^{3} / \mathrm{N} \mathrm{m}$ and $8.015 \times 10^{-16} \mathrm{~m}^{3} / \mathrm{N} \mathrm{m}$.

\section{Conclusions}

(2) In spite of the differences in friction behavior of a$\mathrm{C}: \mathrm{H}$ film under four wear conditions, the values of the wear rate under sand-dust condition were in the same order of magnitude $\left(\times 10^{-16} \mathrm{~m}^{3} / \mathrm{N} \mathrm{m}\right)$ as that of under dry sliding condition without sand, and therefore the sand-dust environment did not lead to a dramatic increase in the wear rate of a-C:H solid lubricant films, and dramatically result in the reduction of friction coefficient.

Figures 5 and $7 \mathrm{a}$ with correct unit 


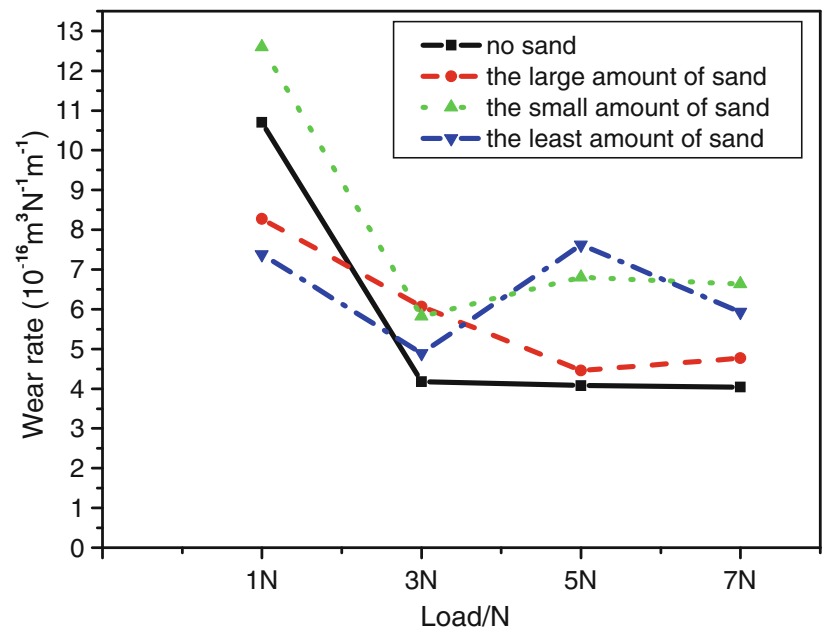

Fig. 5 Variations of wear rates with applied load under four different test conditions with the size range $45-97 \mu \mathrm{m}$ at a frequency of $5 \mathrm{~Hz}$ for $1 \mathrm{~h}$

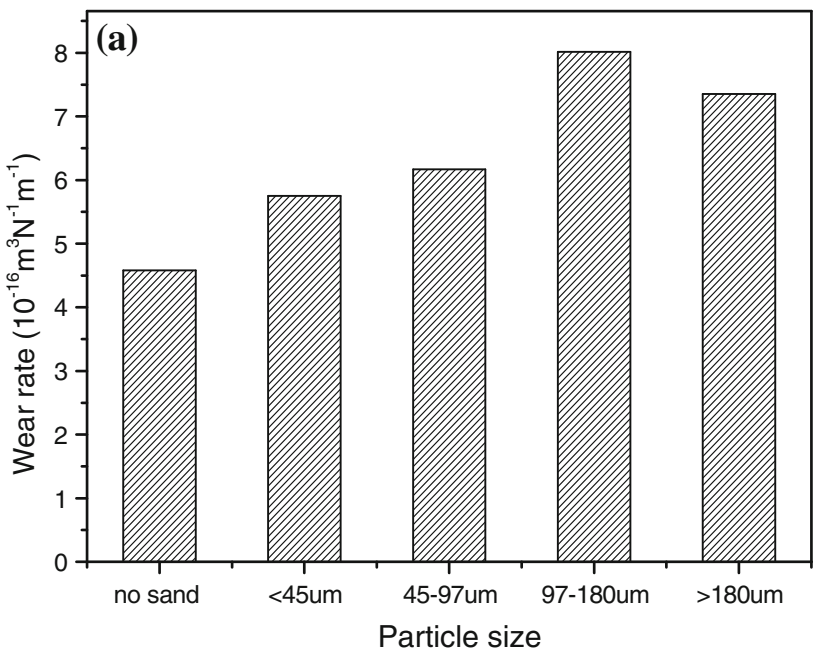

Fig. 7 Variations of wear rates and coefficient of friction with four particle size ranges at applied load of $5 \mathrm{~N}$ and a frequency of $5 \mathrm{~Hz}$ for $1 \mathrm{~h}$. a The large amount of sand condition. $\mathbf{b}$ The least amount of sand condition 